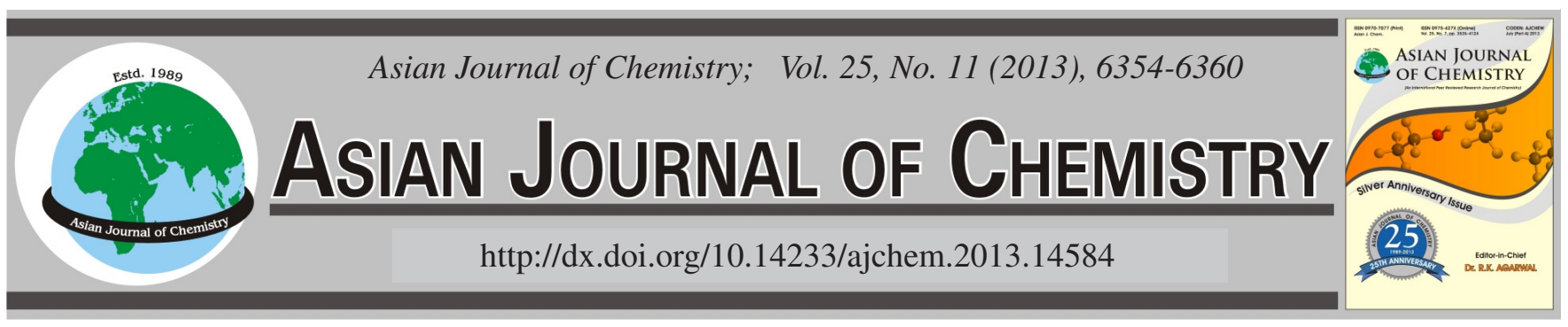

\title{
Studies on the Active Components and Antioxidant Activity of the Extracts from Different Parts of Bamboo
}

\author{
Yu-XIAn Li ${ }^{1, *}$, FAng-Rong Cheng ${ }^{1}$, Yong-Chun JiN ${ }^{2}$ and Ke YuAn ${ }^{2}$
}

${ }^{1}$ College of Pharmacy, Henan University of Traditional Chinese Medicine, Zhengzhou 450008, P.R. China

${ }^{2}$ Zhejiang Agriculture and Forestry University, Lin'an, 311300, P.R. China

*Corresponding author: Tel: +86 371 65962746; E-mail: liyuxian0011@163.com

(Received: 17 September 2012;

Accepted: 10 May 2013)

AJC-13471

This work reports the determination of the total contents of flavonoids and phenolic acids in the extracted matter of the different parts in
the bamboo (leaves, shoots and the bamboo shells) and on this basis, studied the free-radical scavenging function of the ethanol extracts
for the total reducing power (TRP), Fe ${ }^{3+}$ reducing power (FRAP) and the reducing power of DPPH in the bamboo leaves, shoots and
bamboo shells of the two different variants. The experimental results show that there are large amounts of flavonoids and phenolic acids
in the bamboo leaves, shoots and bamboo shells. Through the research of antioxidation, it shows that the ethanol extracts of the bamboo
leaves, shoots and bamboo shells of different variants all have strong free-radical scavenging power and the function of reducing Fe $\mathrm{e}^{3+}$. By
doing the relevant analysis for the contents and antioxidation power of the ethanol extracts of the different parts in bamboo, we know that
there is strong correlation between the contents of flavonoids in the bamboo leaves, shoots and shells and the antioxidation power
conducted by the determining system of DPPH and FRAP. There is also strong correlation between the total contents of phenolic acids
and the antioxidation power determined by the system of TRP, DPPH and FRAP. It is concluded that Phyllostachys pubescens and
Phyllostachys aureosuleata are the kind of bamboos which have strong antioxidant activity and thus provide scientific data for their
further development and exploitation

Key Words: Phyllostachys edulis, Phyllostachys aureosuleata, Flavonoids, Phenols, Antioxidant activity.

\section{INTRODUCTION}

It is well known that there is a strong relationship between the illnesses like the aging, tumor, the low immunologic function and the production of the free radicals. The antioxidants play a very important role in disease-prevention, because they have the ability to remove the free radicals ${ }^{1}$. In recent years, people pay more and more attention to the research of the antioxidation power of the natural plants, for people are afraid of the toxicity and the carcinogenesis of the synthetic antioxidants. The natural products obtained from the natural plants have a very good effect on preventing and curing many kinds of diseases. It shows by research that the antioxidants like flavonoids and phenolic acids contained in many kinds of natural plants have the same function as those in the synthetic antioxidants ${ }^{2,3}$.

Phyllostachys pubescens is a kind of bamboo having the greatest economic value which grows fast with high productivity and wide usage ${ }^{4}$. Phyllostachys aureosuleata has relatively many types among the bamboos of Phyllostachys family both for enjoyment and making food ${ }^{5}$. Nowadays, there has been a wide research for the bioactivity of the chemical composition of the bamboos ${ }^{6}$. The flavonoids contained in the bamboo leaves are both the pharmacological active factor and the important nutrient active factor, having the important health-care functions like anti-lipid peroxidation, anti-aging, removing the free radicals in human bodies, improving the SOD activity, etc. They can be used for the food additives as the functional factors in the functional foods ${ }^{7}$. Bamboo shoots are nutritious with thick crispy meat and the shoots contain many kinds of components needed by the human bodies like amino acids, trace elements, crude fibers, polyphenol and minerals, which have the medical effects like gut purging, constipation prevention, weight losing, preventing the intestinal cancer, anti-aging and cholesterol-reducing ${ }^{8}$. That is to say, at present, the waste left over after processing the bamboo shoots, the bamboo shells, are in fact deserted, except as the industrial fiber or manure. This is wasteful, because the bamboo shells contain rich flavonoids. To our best of knowledge, there have been no reports on the flavonoid extraction and the physiological function of the bamboo shells 9 . 
This work determined the contents of the total flavonoids and phenolic acids in the leaves, shoots and shells of the 8 different bamboo variants and determined their free radical scavenging power and the total reducing power and at the same time, analyzed and evaluated the relationship between the content of the active components and their antioxidation power and thus provided the reference data for their further development and exploitation.

\section{EXPERIMENTAL}

The four variants of Ph. Pubescens i.e., Phyllostachys heterocycla cv. Pubescens, Phyllostachys heterocycla cv. Gracilis, Phyllostachys heterocycla cv. Tao Kiang, Phyllostachys heterocycla and Ph. aureosuleata: the bamboo leaves, shoots, shells of Phyllostachys aureosuleata, Phyllostachys aureosulcataf.-spectabilis, Phyllostachys aureosuleata cv. Aureocarlis and Phyllostachys aureosuleata cv. Pekinensis are all picked up in the bamboo yard of Anji city, Zhejiang Province and they are all identified by the associate professor, Lin Xinchun, the forestry cultivating branch of Zhejiang Agri-Forestry University. The raw materials are cut into small pieces and cleaned and then placed in the oven with $55^{\circ} \mathrm{C}$. After pulverizing them and filtrating through the 40-mesh sift, we get the sample powder for future use.

Infinite M 200 microplate reader(Swiss Tecan); UV-2102 PCS Ultraviolet and visible spectrophotometer (Shanghai Unica Instrument Corporation Limited); KQ-250B type Supersonic cleansing machine (Kunshan Supersonic Instrument Corp. Ltd); R201B Rotating Evaporator (Shanghai Shensheng Biotechnological Corp. Ltd).

1,1-Diphenyl-2-picryl-hydrazyl free radicals (DPPH), $\mathrm{Fe}^{3+}$ tripyradyl triazine (TPTZ), 6-hydroxy- 2,5,7,8-tetramethychroman-2-carboxylic, Trolox are all bought from sigma company. The controls of rutin and gallic acids (both bought from China Pharmaceutical Biological Products-assaying Institute); all the other reagents are home-made analytical reagents.

Preparation of the sample solution: Weigh precisely $1 \mathrm{~g}$ of the powder of bamboo leaves, shoots and shells; then extract twice supersonically by 30 times of $80 \%$ ethanol and each extraction time is for $40 \mathrm{~min}$. After the filtration of the extract liquid, we reduce its pressure and concentrate it and use the $80 \%$ ethanol to the constant volume and then put the sample solution into the refrigerator with the temperature of $4^{\circ} \mathrm{C}$.

\section{Content determination of the active components in the ethanol extracts}

Determination of the total flavonoids ${ }^{10-12}$ : Refer to the developing process of $\mathrm{NaNO}_{2}-\mathrm{Al}\left(\mathrm{NO}_{3}\right)_{3}$ and change it slightly; use rutin concentration as the horizontal ordinate $(\mathrm{X})$ and light absorbancy (Y) as the vertical ordinate to make the standard curve, we will get the regression equation of rutin concentration and absorbancy as follow:

$$
\mathrm{Y}=12.117 \mathrm{X}+0.0006, \mathrm{R}^{2}=0.9999
$$

Draw in respectively a certain amount of sample solution into the flask and according to the method of drawing up the rutin standard curve, we determine the absorbancy and thus calculate the content of the total flavonoids in the samples.
Determination of the total phenolic acids ${ }^{13}$ : Use the method of Folin-Ciocalteu and slightly change it; use the concentration of gallic acids as the horizontal ordinate (X) and light absorbancy (Y) as the vertical ordinate to make the standard curve, we will get the regression equation of gallic acid as follow:

$$
\mathrm{Y}=70.325 \mathrm{X}+0.0002, \mathrm{R}^{2}=0.9999
$$

Draw in respectively a certain amount of sample solution into the flask and according to the method of drawing up the gallic acid standard curve, we determine the absorbancy and thus calculate the content of the total phenolic acid in the samples.

\section{Determination of antioxidant activity}

Determination of scavenging activities on DPPH radicals $\mathrm{DPPH}^{\bullet}$ (1,1-diphenyl-2-picryl-hydrazyl) is a kind of stable free radical with nitrogen as its center in the organic solution. Its ethanol solution is purple-coloured and has a strong adsorption at $517 \mathrm{~nm}$. When there exist the free radical scavenger, due to the pairing of the one-pair electrons of the remover and the DPPH, the adsorption at $517 \mathrm{~nm}$ will decrease and fade and the changing of the adsorption has the quantitative relationship with its accepted electrons. That is, the smaller the adsorption, the stronger the scavenging power of the free radical scavengers and thus it can be analyzed quantitatively by the spectrophotometry. During the process of the sample determination, we use Trolox as the positive controls and calculate the total antioxidation power of the samples and the determined results show the Trolox concentration needed to reach the given concentration of the determined matter. We call this TEAC method (Trolox equivalent antioxidant capacity). TEAC value shows the concentration of the Trolox, and the greater the Trolox concentration, the stronger the free radical scavenging power ${ }^{14-17}$.

The determining method:weigh precisely $20.5 \mathrm{mg}$ DPPH reagents and use $80 \%$ ethanol solution to dissolve it and then switch it into the flask of $100 \mathrm{~mL}$ quantitatively and use $80 \%$ ethanol to dissolve; shake it evenly and we will get the reserve DPPH liquid with the concentration of $205 \mathrm{mg} \mathrm{L}^{-1}$ and then store it into the refrigerator for later use. Before using it, use $80 \%$ ethanol to dilute the DPPH reserve liquid into the solution with the concentration of $82 \mathrm{mg} \mathrm{L}^{-1}$. In the 96-mesh elisa plate add respectively $200 \mu \mathrm{L}$ solution of the various concentrations and $50 \mu \mathrm{L}$ solution of the $82 \mathrm{mg} \mathrm{L}^{-1} \mathrm{DPPH}$. After adding the sample solution, shake it for $30 \mathrm{~s}$ and keep it warm for $30 \mathrm{~min}$ at $24^{\circ} \mathrm{C}$ and then at the wavelength of 517 $\mathrm{nm}$, determine the adsorption value $\left(\mathrm{A}_{\mathrm{p}}\right)$ and at the same time, determine its empty adsorption value $\left(\mathrm{A}_{\mathrm{c}}\right)$ without adding DPPH samples and the adsorption value $\left(\mathrm{A}_{\max }\right)$ adding DPPH but without adding samples $(50 \mu \mathrm{L} 80 \%$ ethanol substitute sample. Use Trolox as the positive controls, the Trolox (X) concentration as the horizontal ordinate and the free radical scavenging rate $(\mathrm{Y})$ as the vertical ordinate to draw the standard curve, we can get the regression equation:

$$
\mathrm{Y}=886.06 \mathrm{X}+31.757, \mathrm{R}^{2}=0.9982
$$

The antioxidation power of the sample is shown by TEAC (Trolox equivalent antioxidant capacity), and the free radical scavenging rate $=1-\left(A_{p}-A_{c}\right) / A_{\max } \times 100 \%$. 
Determination of the reducing power: Take the extract solution of $500 \mu \mathrm{L}$ and put it into the phosphate buffer solution of $2.5 \mathrm{~mL}\left(0.2 \mathrm{~mol} \mathrm{~L}^{-1}, \mathrm{pH}\right.$ value is 6.6$)$ and then add the $2.5 \mathrm{~mL}$ of the $1 \% \mathrm{~K}_{3} \mathrm{Fe}(\mathrm{CN})_{6}$ and put it into the $50{ }^{\circ} \mathrm{C}$ water to warm for $0.5 \mathrm{~h}$ and add $2.5 \mathrm{~mL}$ of the $10 \%$ trichloroacetic acid, after even shaking, centrifugate it for $10 \mathrm{~min}$. Take the supernate liquid $2.5 \mathrm{~mL}$, add the distilled water of $2.5 \mathrm{~mL}$ quickly and mix them evenly with the $0.5 \mathrm{~mL}$ of $0.1 \%$ ferric trichloride and make the colorimetric estimation at the wavelength of $700 \mathrm{~nm}$. Use the fresh Trolox working solution to check it and use Trolox concentration (0.04-0.80 $\left.\mathrm{mg} \mathrm{mL}^{-1}\right)$ as the horizontal ordinate, the light adsorption as the vertical ordinate to make the curve and the obtained regression equation is $\mathrm{Y}=1.184 \mathrm{X}+0.2997\left(\mathrm{R}^{2}=0.9963\right)$. Calculate the overall antioxidation power through standard curve and its result is shown by TEAC value.

Determination of total antioxidant activity (ferric reducing antioxidant power, FRAP): The principle of FRAP (ferric reducing antioxidant power) ${ }^{18-20}$ is as follows: $\mathrm{Fe}^{3+}$ (tripyradyl triazine, TPTZ) can be reduced to Ferrous iron by the reducing matter in the samples and it appears the colour of blue and has the greatest adsorption at $593 \mathrm{~nm}$ and thus we can calculate its antioxidation power according to its adsorption values.

Take respectively acetic acid buffer $0.1 \mathrm{~mol} \mathrm{~L}^{-1}$ (pH 3.6), $10 \mathrm{mmol} \mathrm{L}^{-1}$ TPTZ (dissolved in $40 \mathrm{mmol} \mathrm{L}^{-1}$ hydrochloric acid) and $20 \mathrm{mmol} \mathrm{L}^{-1}$ ferric trichloride solution and mixed them by the volume ratio of 10:1:1. Take the reagents of 300 $\mu \mathrm{L}$ FRAP and the extract liquid of $10 \mu \mathrm{L}$, let them react for 10 min and then measure its adsorption value at $593 \mathrm{~nm}$. Use the $80 \%$ ethanol as the substitute of the samples and add FRAP working solution as the blank solution. Calculate the antioxidation power of the samples according to various adsorption values. We know that the bigger the adsorption value, the stronger their antioxidation power. Use Trolox solution as the positive control, the Trolox (X) concentration as the horizontal ordinate and the adsorption value (Y) as the vertical ordinate to draw the standard curve, we can get the regression equation $\mathrm{Y}=8.8014 \mathrm{X}+0.0218, \mathrm{R}^{2}=0.9976$. The antioxidation power of the samples is shown by TEAC (Trolox equivalent antioxidant capacity).

\section{RESULTS AND DISCUSSION}

Content comparison of the total flavonoids and the total phenolic acids: Adopt the $\mathrm{NaNO}_{2}-\mathrm{Al}\left(\mathrm{NO}_{3}\right)_{3}$ developing process to determine the total contents of flavonoids in the leaves, shoots and shells of the 8 bamboo variants and the results can be shown in Fig. 1. Fig. 1 showed that there is small difference in the total flavonoid contents between the different bamboo variants. The flavonoid content in bamboo leaves is obviously higher than in the shoots. The flavonoid content in shells is slightly higher than in the shoot body. Comparing the total flavonoid contents in the bamboo leaves, we know that the Phyllostachys pubescens bamboo has the highest content, while the phyllostachys aureosulcata has the smallest content. Comparing the total flavonoid contents in the bamboo shoot bodies, we find that the highest flavonoid content is in Phyllostachys heteroclada and the lowest content is in Phyllostachys pubescens. Comparing the total flavonoid contents in the bamboo shells, we know that the Phyllostachys pubescens is the highest while the Phyllostachys heteroclada is the smallest.

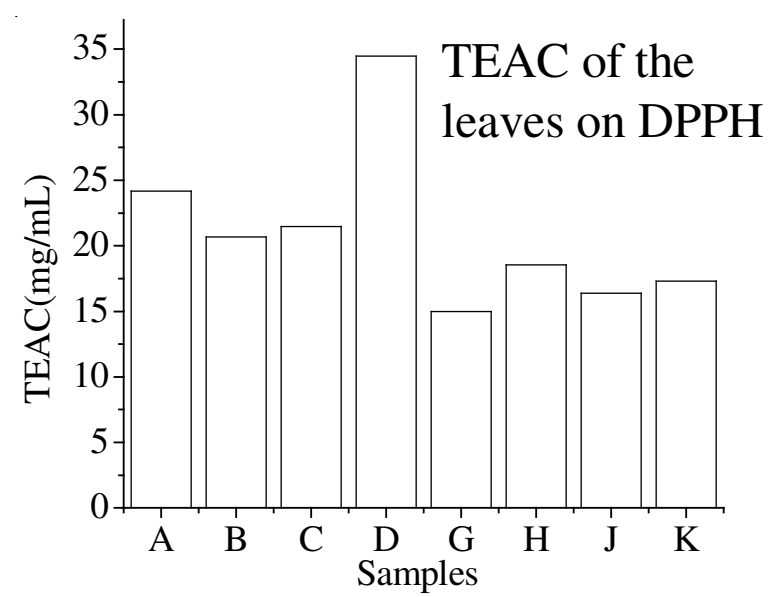

Fig. 1. TEAC values of the leaves of bamboo; A: Pubescens; B: Gracilis; C: Tao Kiang; D: Heterocycla; G: Aureosuleata; H: Aureocarlis; J: Spectabilis; K: Pekinensis

Adopt the Folin-Ciocalteu method to measure the total contents of phenolic acid in the extracts of the eight bamboo variants, the results are summarized in Table-1. From Table-1, we find that the total contents of phenolic acid in the different variants of bamboo leaves, shoots and shells are similar. But in the bamboo leaves the phenolic acid content is clearly higher than that in the bamboo shoots and shells. Among the bamboo leaves, the phenolic acid content in Phyllostachys pubescens is the highest and the Phyllostachys aureosulcata is the

TABLE-1

CONEENTS OF TOTAL FLAVONOIDS AND TOTAL PHENOLS IN LEAVES, SHOOTS AND SHELLS OF EIGHT CULTIVARS OF BAMBOO $(\mathrm{n}=3)$

\begin{tabular}{|c|c|c|c|c|c|c|}
\hline \multirow[b]{2}{*}{ Samples } & \multicolumn{2}{|c|}{ Leaf of bamboo } & \multicolumn{2}{|c|}{ Shoot of bamboo } & \multicolumn{2}{|c|}{ Shell of bamboo } \\
\hline & $\begin{array}{c}\text { Content of TF } \\
\left(\mathrm{mg} \mathrm{RE} \mathrm{g}^{-1}\right)\end{array}$ & $\begin{array}{l}\text { Content of TPA } \\
\left(\mathrm{mg} \mathrm{GAE} \mathrm{g} \mathrm{g}^{-1}\right)\end{array}$ & $\begin{array}{l}\text { Content of TF } \\
\left(\mathrm{mg} \mathrm{RE} \mathrm{g}^{-1}\right)\end{array}$ & $\begin{array}{c}\text { Content of TPA } \\
\left(\mathrm{mg} \mathrm{GAE} \mathrm{g}^{-1}\right)\end{array}$ & $\begin{array}{l}\text { Content of TF } \\
\left(\mathrm{mg} \mathrm{RE} \mathrm{g}^{-1}\right)\end{array}$ & $\begin{array}{c}\text { Content of TPA } \\
\left(\mathrm{mg} \mathrm{GAE} \mathrm{g}^{-1}\right)\end{array}$ \\
\hline Pubescens & $23.358 \pm 0.014$ & $29.586 \pm 0.009$ & $3.088 \pm 0.002$ & $13.087 \pm 0.001$ & $5.455 \pm 0.019$ & $15.622 \pm 0.011$ \\
\hline Gracilis & $21.434 \pm 0.033$ & $29.283 \pm 0.010$ & $2.363 \pm 0.010$ & $12.124 \pm 0.022$ & $6.075 \pm 0.011$ & $15.315 \pm 0.015$ \\
\hline Tao Kiang & $21.185 \pm 0.017$ & $28.056 \pm 0.003$ & $3.352 \pm 0.005$ & $13.893 \pm 0.001$ & $5.022 \pm 0.013$ & $15.161 \pm 0.031$ \\
\hline Heterocycla & $25.559 \pm 0.033$ & $30.496 \pm 0.009$ & $1.938 \pm 0.021$ & $10.672 \pm 0.038$ & $6.325 \pm 0.008$ & $16.692 \pm 0.028$ \\
\hline Aureosuleata & $17.678 \pm 0.014$ & $25.652 \pm 0.009$ & $2.356 \pm 0.023$ & $12.053 \pm 0.001$ & $2.138 \pm 0.001$ & $12.598 \pm 0.001$ \\
\hline Aureocarlis & $20.103 \pm 0.033$ & $28.501 \pm 0.010$ & $3.163 \pm 0.026$ & $13.444 \pm 0.022$ & $1.346 \pm 0.010$ & $9.264 \pm 0.021$ \\
\hline spectabilis & $18.173 \pm 0.017$ & $28.254 \pm 0.003$ & $4.088 \pm 0.033$ & $14.642 \pm 0.010$ & $1.292 \pm 0.002$ & $9.103 \pm 0.004$ \\
\hline Pekinensis & $18.668 \pm 0.033$ & $29.349 \pm 0.062$ & $2.763 \pm 0.012$ & $12.529 \pm 0.038$ & $1.349 \pm 0.012$ & $9.359 \pm 0.021$ \\
\hline
\end{tabular}


smallest. In the bamboo shoots, the highest content is in Phyllostachys heteroclada and the lowest content is in Phyllostachys pubescens. Comparing the total phenolic acid contents in the bamboo shells, we know that the Phyllostachys pubescens is the highest while the Phyllostachys heteroclada is the smallest.

Scavenging power of DPPH: The experimental results show that the extracts of bamboo leaves, shoots and shells all have relatively higher scavenging rate for DPPH free radicals and we know that the scavenging rates will increase with the rising of the extract concentration. When the concentration degree reaches to a certain value, there will be no correlation between the scavenging rate and its concentration. Therefore, in order to better explain the scavenging capacity of the extracts for the free radicals, this experiment chooses the concentration $\left(\mathrm{IC}_{50}\right.$ value) when the scavenging rate is $50 \%$. And then use Trolox as the posititve control to calculate the TEAC value. The TEAC value shows the equivalent Trolox content of the samples to be measured when it reaches half of its scavenging rate. The higher the TEAC value, the stronger the scavenging power. The experimental results can be seen in Figs. 1-3 and Table-2.

In the DPPH evaluating system, by comparing Figs. 1-3 and Table-2, we know that there are differences of various

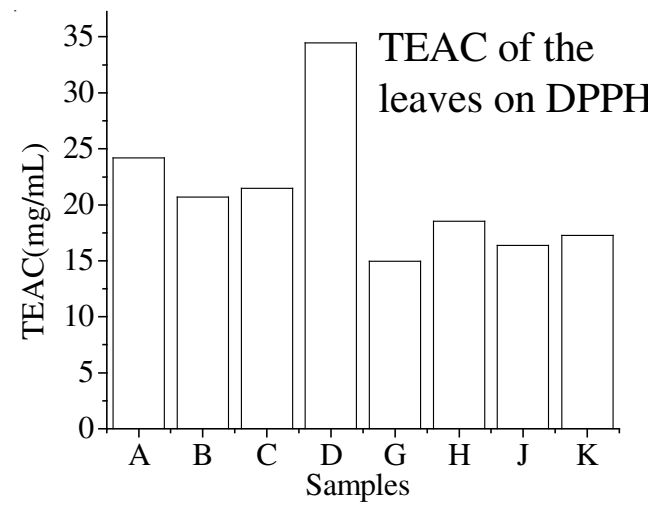

Fig. 2. TEAC values of the shoots of bamboo; A: Pubescens; B: Gracilis; C: Tao Kiang; D: Heterocycla; G: Aureosuleata; H: Aureocarlis; J: Spectabilis; K: Pekinensis

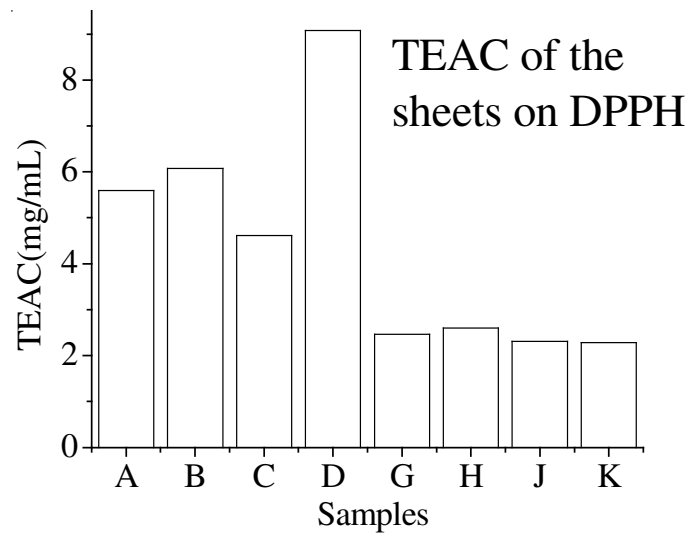

Fig. 3. TEAC values of the sheets of bamboo; A: Pubescens; B: Gracilis; C: Tao Kiang; D: Heterocycla; G: Aureosuleata; H: Aureocarlis; J: Spectabilis; K: Pekinensis

degrees in the scavenging power for the DPPH free radicals of the bamboo leaves and shoots of different bamboo variants. The scavenging power of the Phyllostachys pubescens is the highest in the bamboo leaves, while the Phyllostachys aureosulcata is the lowest. In the bamboo shoots, the strongest is Phyllostachys heteroclada, the smallest is Phyllostachys aureosulcata. In the bamboo shells, the strongest scavenging power is in golden thread moso bamboo and the smallest is the Beijing bamboo. The experimental results show that there is certain degree of scavenging power in different parts of the bamboo in different bamboo variants and the concrete antioxidant system and its antioxidant active experiments are still to be discussed further.

TRP method and FRAP method: There is a relationship between the reducing power of the antioxidants and the inoxidizability. The stronger the reducing power, the more powerful the antioxidating ability. Therefore, we can know the antioxidant power by calculating their reducing capability. Both FRAP and TRP methods are to check their reducing abilities by using antioxidants in the samples as the reducing agents. They are not directed at the scavenging activity for a certain free radical, but reflect the total antioxidant capability. Therefore, they are more suitable for evaluating the natural

\begin{tabular}{|c|c|c|c|c|c|c|c|c|c|}
\hline \multirow{3}{*}{ Variety } & \multicolumn{8}{|c|}{$\begin{array}{l}\text { TABLE-2 } \\
\text { SCAVENGING CAPACITY AND THE TOTAL REDUCING CAPACITY IN THE LEAVES, } \\
\text { SHOOTS AND SHELLS OF EIGHT CULTIVARS OF BAMBOO }(\mathrm{n}=3)\end{array}$} & \\
\hline & \multicolumn{3}{|c|}{ TEAC in leaf of bamboo } & \multicolumn{3}{|c|}{ TEAC in shoot of bamboo } & \multicolumn{3}{|c|}{ TEAC in sheel of bamboo } \\
\hline & DPPH & TRP & FRAP & DPPH & TRP & FRAP & DPPH & TRP & FRAP \\
\hline Pubescens & $\begin{array}{c}24.177 \pm \\
0.006\end{array}$ & $\begin{array}{c}40.185 \pm \\
2.109\end{array}$ & $\begin{array}{c}21.782 \pm \\
0.821\end{array}$ & $\begin{array}{c}2.191 \pm \\
0.061\end{array}$ & $\begin{array}{c}15.741 \pm \\
0.569\end{array}$ & $\begin{array}{c}3.029 \pm \\
0.056\end{array}$ & $\begin{array}{c}18.973 \pm \\
0.056\end{array}$ & $\begin{array}{c}5.597 \pm \\
0.016\end{array}$ & $\begin{array}{c}11.732 \pm \\
0.006\end{array}$ \\
\hline Gracilis & $\begin{array}{c}20.241 \pm \\
0.041\end{array}$ & $\begin{array}{c}49.861 \pm \\
1.241\end{array}$ & $\begin{array}{c}18.301 \pm \\
0.651\end{array}$ & $\begin{array}{c}1.995 \pm \\
0.022\end{array}$ & $\begin{array}{c}9.512 \pm \\
0.001\end{array}$ & $\begin{array}{c}2.329 \pm \\
0.091\end{array}$ & $\begin{array}{c}24.877 \pm \\
0.491\end{array}$ & $\begin{array}{c}6.094 \pm \\
0.022\end{array}$ & $\begin{array}{c}8.578 \pm \\
0.003\end{array}$ \\
\hline Tao Kiang & $\begin{array}{c}21.467 \pm \\
0.037\end{array}$ & $\begin{array}{c}50.989 \pm \\
2.963\end{array}$ & $\begin{array}{c}18.339 \pm \\
3.389\end{array}$ & $\begin{array}{c}2.189 \pm \\
0.005\end{array}$ & $\begin{array}{c}11.913 \pm \\
1.344\end{array}$ & $\begin{array}{c}3.157 \pm \\
0.005\end{array}$ & $\begin{array}{c}16.172 \pm \\
0.915\end{array}$ & $\begin{array}{c}4.608 \pm \\
0.005\end{array}$ & $\begin{array}{c}8.643 \pm \\
0.015\end{array}$ \\
\hline Heterocycla & $\begin{array}{c}34.486 \pm \\
0.061\end{array}$ & $\begin{array}{c}45.793 \pm \\
1.948\end{array}$ & $\begin{array}{c}24.065 \pm \\
1.537\end{array}$ & $\begin{array}{c}1.585 \pm \\
0.006\end{array}$ & $\begin{array}{c}8.068 \pm \\
1.052\end{array}$ & $\begin{array}{c}2.062 \pm \\
0.008\end{array}$ & $\begin{array}{c}24.223 \pm \\
1.108\end{array}$ & $\begin{array}{c}9.077 \pm \\
0.076\end{array}$ & $\begin{array}{c}10.014 \pm \\
0.018\end{array}$ \\
\hline Aureosuleata & $\begin{array}{c}14.966 \pm \\
0.006\end{array}$ & $\begin{array}{c}39.961 \pm \\
3.642\end{array}$ & $\begin{array}{c}13.282 \pm \\
1.791\end{array}$ & $\begin{array}{c}1.326 \pm \\
0.011\end{array}$ & $\begin{array}{c}8.162 \pm \\
2.675\end{array}$ & $\begin{array}{c}2.275 \pm \\
0.093\end{array}$ & $\begin{array}{c}15.577 \pm \\
0.893\end{array}$ & $\begin{array}{c}2.468 \pm \\
0.008\end{array}$ & $\begin{array}{c}2.852 \pm \\
0.093\end{array}$ \\
\hline Aureocarlis & $\begin{array}{c}18.531 \pm \\
0.002\end{array}$ & $\begin{array}{c}31.799 \pm \\
1.109\end{array}$ & $\begin{array}{c}15.003 \pm \\
0.046\end{array}$ & $\begin{array}{c}2.215 \pm \\
0.001\end{array}$ & $\begin{array}{c}16.373 \pm \\
0.026\end{array}$ & $\begin{array}{l}3.111 \pm \\
0.0444\end{array}$ & $\begin{array}{c}14.885 \pm \\
0.110\end{array}$ & $\begin{array}{c}2.597 \pm \\
0.0122\end{array}$ & $\begin{array}{c}2.249 \pm \\
0.044\end{array}$ \\
\hline Spectabilis & $\begin{array}{c}16.383 \pm \\
0.003\end{array}$ & $\begin{array}{c}37.677 \pm \\
1.241\end{array}$ & $\begin{array}{c}14.778 \pm \\
0.210\end{array}$ & $\begin{array}{c}2.276 \pm \\
0.004\end{array}$ & $\begin{array}{c}17.819 \pm \\
0.033\end{array}$ & $\begin{array}{l}3.253 \pm \\
0.0522\end{array}$ & $\begin{array}{c}16.266 \pm \\
0.042\end{array}$ & $\begin{array}{c}2.308 \pm \\
0.021\end{array}$ & $\begin{array}{c}2.729 \pm \\
0.053\end{array}$ \\
\hline Pekinensis & $\begin{array}{c}17.280 \pm \\
0.002\end{array}$ & $\begin{array}{c}39.033 \pm \\
1.963\end{array}$ & $\begin{array}{c}15.089 \pm \\
0.091\end{array}$ & $\begin{array}{c}2.047 \pm \\
0.011\end{array}$ & $\begin{array}{c}13.364 \pm \\
0.012\end{array}$ & $\begin{array}{c}2.951 \pm \\
0.084\end{array}$ & $\begin{array}{c}13.512 \pm \\
0.012\end{array}$ & $\begin{array}{c}2.287 \pm \\
0.031\end{array}$ & $\begin{array}{c}3.043 \pm \\
0.093\end{array}$ \\
\hline
\end{tabular}


products which contain many different components and scavenge different free radicals. Within a certain range of concentrations, as the sample concentration rises, the adsorption value has the tendency to increase linearly. The experimental results show that in the TRP system, the concentrations of the ethanol extracts of the bamboo leaves in different species of bamboos are between 2-14 $\mathrm{mg} \mathrm{mL}^{-1}$. The concentrations of the ethanol extracts of the bamboo shoots in different species of bamboos are between 8-24 $\mathrm{mg} \mathrm{mL}^{-1}$. The concentrations of the ethanol extracts of the bamboo shells in different species of bamboos are between 6-16 $\mathrm{mg} \mathrm{mL}^{-1}$ and the concentrations of the ethanol liquids of the positive control Trolox are between 0.0744-0.1984 $\mathrm{mg} \mathrm{mL}^{-1}$, which shows that there is a good linear relationship between adsorption and its concentration. In the FRAP system, the concentrations of the ethanol extracts of the bamboo leaves in different species of bamboos are between 1-8 $\mathrm{mg} \mathrm{mL}^{-1}$. The concentrations of the ethanol extracts of the bamboo shoots in different species of bamboos are between $16-30 \mathrm{mg} \mathrm{mL}^{-1}$. The concentrations of the ethanol extracts of the bamboo shells in different species of bamboos are between 2-24 $\mathrm{mg} \mathrm{mL}^{-1}$ and the concentrations of the ethanol liquids of the positive control Trolox are between $0.0248-0.0868 \mathrm{mg} \mathrm{mL}^{-1}$. At this time, there is a good linear relationship between adsorption and its concentration. The results of the reducing power of the bamboo leaves, shoots and shells in the 8 bamboo variants by the TRP and FRAP methods can be seen in Figs. 4-9.

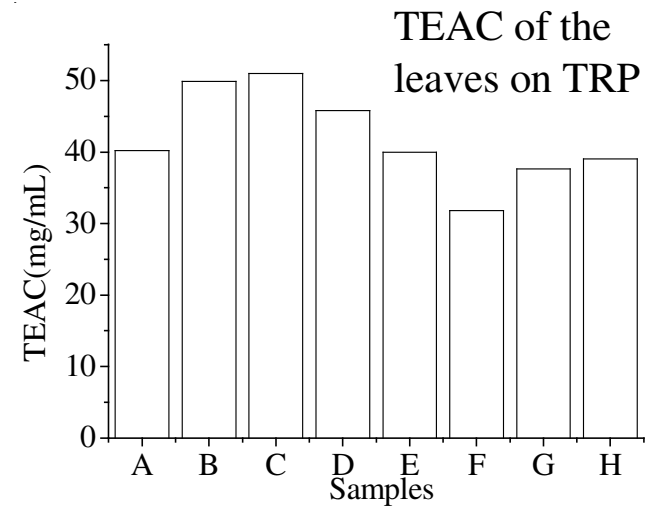

Fig. 4. TEAC values of the leaves of bamboo; A: Pubescens; B: Gracilis; C: Tao Kiang; D: Heterocycla; G: Aureosuleata; H: Aureocarlis; J: Spectabilis; K: Pekinensis

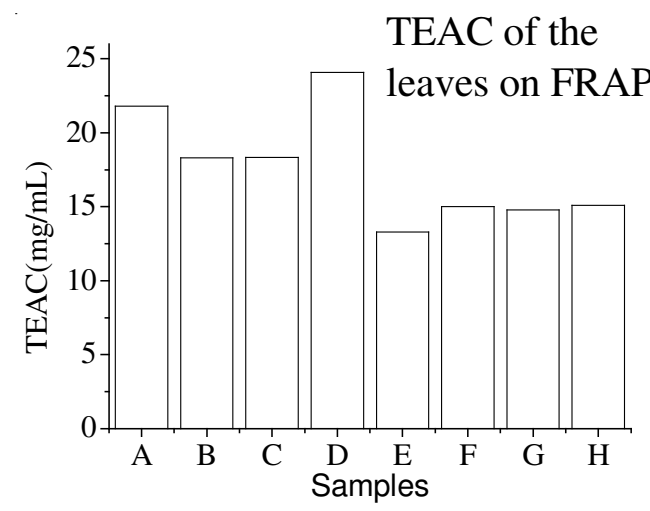

Fig. 5. TEAC values of the shoots of bamboo; A: Pubescens; B: Gracilis; C: Tao Kiang; D: Heterocycla; G: Aureosuleata; H: Aureocarlis; J: Spectabilis; K: Pekinensis
TEAC of the

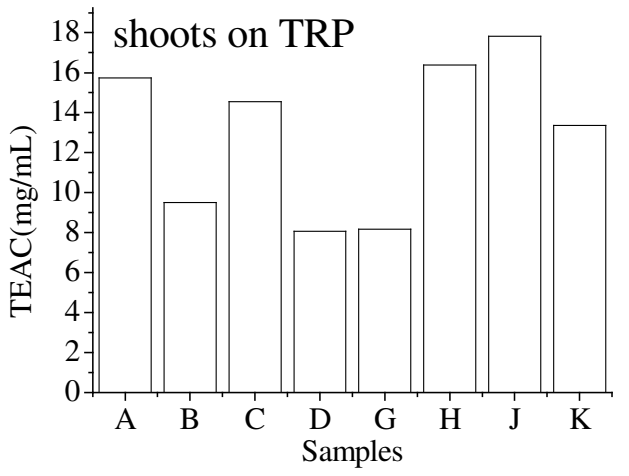

Fig. 6. TEAC values of the shoots of bamboo; A: Pubescens; B: Gracilis; C: Tao Kiang; D: Heterocycla; G: Aureosuleata; H: Aureocarlis; J: Spectabilis; K: Pekinensis

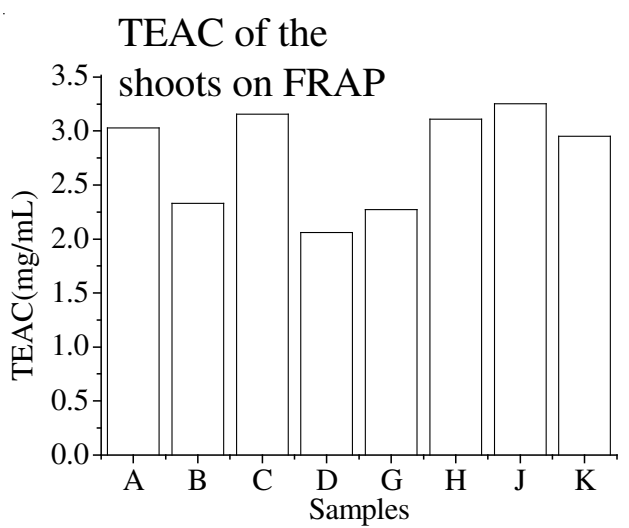

Fig. 7. TEAC values of the shoots of bamboo; A: Pubescens; B: Gracilis; C: Tao Kiang; D: Heterocycla; G: Aureosuleata; H: Aureocarlis; J: Spectabilis; K: Pekinensis

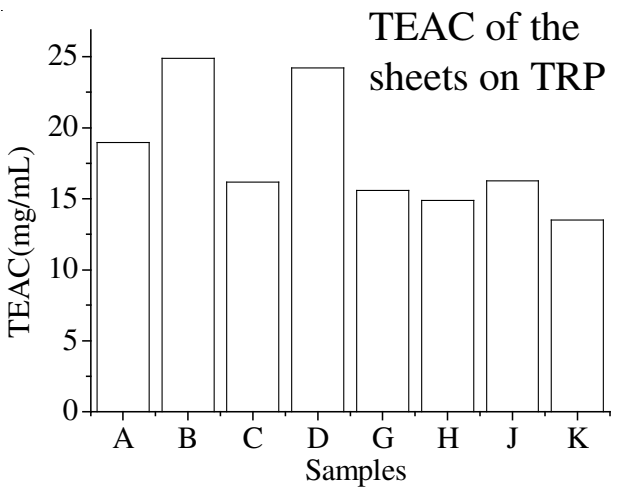

Fig. 8. TEAC values of the sheels of bamboo; A: Pubescens; B: Gracilis; C: Tao Kiang; D: Heterocycla; G: Aureosuleata; H: Aureocarlis; J: Spectabilis; K: Pekinensis

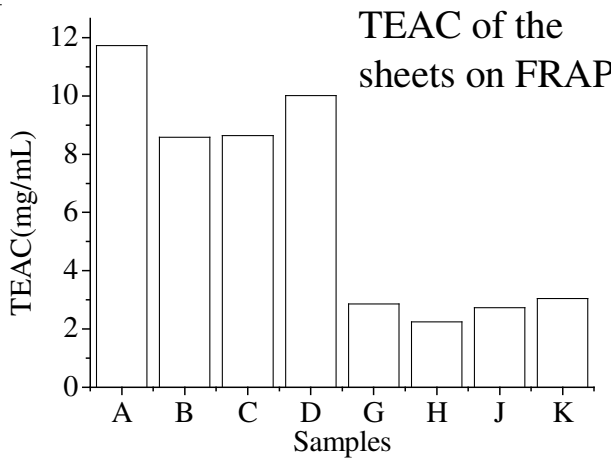

Fig. 9. TEAC values of the sheels of bamboo; A: Pubescens; B: Gracilis; C: Tao Kiang; D: Heterocycla; G: Aureosuleata; H: Aureocarlis; J: Spectabilis; K: Pekinensis 
The results show that the reducing power of the bamboo leaves, shoots and shells and the concentrations of the solutions to be tested have an obvious positive correlation. So in this research, we choose TEAC value as the indicator, that is, the Trolox content of the tested material when the adsorption reaches $50 \%$. The bigger the TEAC value, the stronger the reducing power of the material, which can be shown in Table2. It is known from Table-2 that for the methods of TRP and FRAP, the strongest reducing power in the bamboo leaves is Phyllostachys heterocycla cv. Gracilis, and the lowest is Phyllostachys heterocycla cv. Viridisulcata. The strongest reducing power in the bamboo shoots is Phyllostachys aureosulcataf.-spectabilis, the lowest is Phyllostachys heterocycla. The strongest reducing power in the bamboo shells is Phyllostachys heterocycla cv. Pubescens and the lowest is Phyllostachys aureosuleata cv. Aureocarlis.

Relativity analysis between the TF and TPA contents and antioxidant capacity: After we make the correlate analysis for the total flavonoids and phenolic acids and their antioxidant capacity in the ethanol extracts of the bamboo leaves, shoots and shells, we can know the results in Tables 3-5. From these tables, there is a clear correlation between the contents of the active components and their antioxidant capacity of the bamboo leaves, shoots and shells. Among them, the total flavonoid content in the bamboo shoots and shells has an extreme correlation with the antioxidant capacity in the three evaluating systems $(p<0.01)$, while the total flavonoid content in the bamboo leaves has small correlation with the antioxidant capacity in DPPH evaluating system. It is therefore shown that no matter in Phyllostachys heterocycla cv. Pubescens or in Phyllostachys aureosuleata, the flavonoids in them play the part of antioxidant capacity to a certain degree. And the antioxidant mechanism of the bamboo leaves needs to be further studied.

The total phenol acid content in the bamboo shoots and shells has an extreme correlation with the antioxidant capacity in the three evaluating systems $(p<0.01)$ and the total phenol acid content in the bamboo leaves only has a little correlation with the antioxidant capacity in the three evaluating systems. This shows that the total flavonoids and phenol acids play a leading role in scavenging DPPH and in reducing $\mathrm{Fe}^{3+}$ and the higher the contents of total flavonoids and phenol acids, the stronger the scavenging power for the free radicals. It's therefore known that the phenolic acid compounds are the main antioxidant components in the bamboo leaves and shoots. The results of the three methods used in measuring the antioxidant capacity have clear correlation and therefore the three methods can all be used in determining and evaluating the antioxidant capacity of the bamboos.

\section{Conclusion}

This thesis extracts the different parts of the 8 species of Phyllostachys heterocycla cv. Pubescens and Ph. aureosuleata and makes the content determination of the total flavonoids and phenol acids in the ethanol extracts. Meanwhile we adopt the methods of DPPH, FRAP and TRP to have a external determination on the antioxidant capacity of the ethanol extracts. The results show that the extracts of bamboo leaves, shoots and shells all have a strong scavenging power for DPPH and FRAP free radicals and they also have relatively strong reducing

TABLE-3

RELATIVITY ANALYSIS BETWEEN THE TF AND TPA CONTENT AND ANTIOXIDANT CAPACITY OF LEAVES

\begin{tabular}{cccccc}
\hline & Content of TF & Content of TPA & DPPH & TRP & FRAP \\
\hline Content of TF & 1 & $0.741^{*}$ & $0.958^{* *}$ & 0.430 & $0.980^{* *}$ \\
Content of TPA & & 1 & $0.716^{*}$ & 0.185 & $0.745^{*}$ \\
DPPH & & 1 & 0.409 & $0.946^{* *}$ \\
TRP & & & 1 & 0.488 \\
FRAP & & & & 1 \\
\hline
\end{tabular}

*Correlation is significant at the 0.05 level (2-tailed); ${ }^{* *}$ Correlation is significant at the 0.01 level; $\mathrm{TF}=$ Total flavonoid; TPA=Total phenolic acid.

\begin{tabular}{cccccc}
\multicolumn{7}{c}{ TABLE-4 } \\
RELATIVITY ANALYSIS BETWEEN THE TF AND TPA CONTENT AND ANTIOXIDANT CAPACITY OF SHOOTS \\
\hline \\
Content of TF & Content of TPA & DPPH & TRP & FRAP \\
\hline Content of TF & 1 & $0.977^{* * *}$ & $0.776^{*}$ & $0.924^{* *}$ & $0.916^{* * *}$ \\
TPA content & 1 & & $0.894^{* *}$ & $0.919^{* *}$ \\
DPPH & & 1 & $0.886^{* *}$ & $0.861^{* *}$ \\
TRP & & & 1 & $0.968^{* *}$ \\
FRAP & & & & 1 \\
\hline
\end{tabular}

*Correlation is significant at the 0.05 level (2-tailed); **Correlation is significant at the 0.01 level; TF=Total flavonoid; TPA=Total phenolic acid.

TABLE-5

RELATIVITY ANALYSIS BETWEEN THE TF AND TPA CONTENT AND ANTIOXIDANT CAPACITY OF SHELLS

\begin{tabular}{cccccc}
\hline & Content of TF & Content of TPA & DPPH & TRP & FRAP \\
\hline Content of TF & 1 & $0.966^{* *}$ & $0.915^{* *}$ & $0.842^{* *}$ & $0.948^{* *}$ \\
TPA content & & 1 & $0.868^{* *}$ & $0.755^{*}$ & $0.917^{* *}$ \\
DPPH & & 1 & $0.881^{* *}$ & $0.848^{* *}$ \\
TRP & & & 1 & 0.699 \\
FRAP & & & & 1 \\
\hline
\end{tabular}

*Correlation is significant at the 0.05 level (2-tailed); **Correlation is significant at the 0.01 level; TF=Total flavonoid; TPA=Total phenolic acid. 
capacity for $\mathrm{Fe}^{3+}$. And within a certain range of extract mass and concentration, different extracts have the obvious linear relationship with their antioxidant capacity. The overall evaluating results show that the contents of the total flavonoids and phenol acids in the different variants of the same species have the similar antioxidant capacity and there are big differences in the different bamboo species. The flavonoid compounds are rich in the bamboo leaves and they are one of the main antioxidant active components. Therefore, there is a potential practical value in using the raw materials of $P h$. pubescens and Phyllostachys aureosuleata to prepare the natural antioxidants of flavonoids. This research provides the scientific data for further studies and exploitation of the functions of the different variants of Ph. Pubescens and Phyllostachys aureosuleata.

\section{ACKNOWLEDGEMENTS}

The authors are grateful to the Zhejiang Agriculture and Forestry University for performing Universal Microplate Spectrophotometer and microorganism experiment.

\section{REFERENCES}

1. O.I. Aruoma, J. Am. Oil Chem. Soc., 75, 199 (1998).

2. S. Caillet, Food Chem., 100, 542 (2007).
3. G.G. Xie, D.I. Cao and J.I. Wang, J. North Univ. China (Nat. Sci. Ed.). 28, 64 (2007)

4. Y.X. Zhang and C.H. He, J. Chem. Eng. Chin. Univ., 5, 690 (2006).

5. B. Lu, X. Wu, X. Tie and Y. Zhang, Food Chem. Toxicol., 43, 783 (2005).

6. F. Jin, J. China Condiment., 4, 55 (2008)

7. A.P. Li, B.X. Xie, Q.P. Zhong and J.K. Tao, Food Sci., 29, 97 (2008).

8. L. Jiang, L.K. Jiang and K.W. Chen, Nat. Prod. Res. Develop., 21, 146 (2009).

9. J.W. Chen, B. Hu and S. Zhao, Chin. J. Luminesc., 26, 664 (2005)

10. Y.S. Velioglu, G. Mazza, L. Gao and B.D. Oomash, J. Agric. Food Chem., 46, 4113 (1998).

11. Y.F. Yang and C.L. Huang, J. Bamboo Res., 1, 56 (2009).

12. H.Y. Huang, B. Deng and G.B. Jiang, Lishizhen Med. Mater. Med. Res., 6, 1443 (2009).

13. C.H. Wang, X.H. Zhong, L.D. Li, M. Zhang and Z.H. Chu, Prog. Modern Biomed., 9, 4540 (2009).

14. H. Ye, C.H. Zhou, Y. Sun, X. Zhang, J. Liu, Q.H. Hu and X.X. Zeng, Eur. Food Res. Technol., 230, 101 (2009).

15. X.T. Chen, K. Yuan and H.L. Liu, J. FoodAgric. Environ., 8, 132 (2010).

16. M. Oyaizu, Japanese J. Nutr., 44, 307 (1986).

17. M. Patricia, M. Suhaila, M.M. Noordin, M. Kharidah and H.M. Cheng, J. Appl. Phycol., 20, 67 (2008).

18. I.F. Benzie and J.J. Strain, Anal. Biochem., 239, 70 (1996).

19. Y.H. Gao, J.P. Zheng, C.Y. Zhu, Y.J. Li, Y. Ke and K. Bian, Chin. Pharm. J., 24, 1863 (2008).

20. P.K. Wilmsen, D.S. Spada and M. Salvador, J. Agric. Food Chem., 53, 4757 (2005). 